\title{
A Ground-Beetle, Chlaenius hamifer Chaudoir, New to Korea (Coleoptera: Carabidae)
}

\author{
Jong Kyun Park*, Jinyoung Park \\ Department of Applied Biology, College of Ecology and Environmental Science, \\ Kyungpook National University, Sangju 742-711, Korea
}

\begin{abstract}
Chlaenius is a large and diverse genus of ground beetle. This colorful beetle recognized from its pubescent elytra and pungent defensive secretions. Subgenus Pachydinodes belonging to the genus Chlaenius were reported eight species from Palaearctic, among them four species, Chlaenius (Pachydinodes) abstersus Bates, C. (P.) pictus Chaudoir, C. (P.) tetragonoderus Chaudoir, C. (P.) virgulifer Chaudoir were reported in Korea up to now. In here, Chlaenius hamifer Chaudoir are report firstly in Korea. Description and photo of adult and aedeagus are provided.
\end{abstract}

Keywords: taxonomy, new record, Chlaenius hamifer, Coleoptera, Korea

\section{INTRODUCTION}

Eight species of the subgenus Pachydinodes were reported from Palaearctic region (Kirschenhofer, 2003), among them four species, Chlaenius (Pachydinodes) abstersus Bates, $C$. (P.) pictus Chaudoir, $C$. (P.) tetragonoderus Chaudoir, $C$. $(P$.) virgulifer Chaudoir were reported in Korea up to now (The Entomological Society of Korea and Korean Society of Applied Entomology, 1994; Park and Paik, 2001). Members of this subgenus are characterized and easily distinguished by external morphology, like shapes of elytral spot or bend at apex and colorful diversity at head and pronotum dorsally. These species have well developed hind wing and tarsal claws which can be able to live on the tree flying and catching and feeding the small worms etc. (Nakane, 1986).

\section{SYSTEMATIC ACCOUNTS}

Order Coleoptera

Family Carabidae

Genus Chlaenius Bonelli, 1810

Subgenus Pachydinodes Kuntzen, 1919
Key to species of the subgenus Pachydinodes from Korea

1. Elytra with yellowish spot or bend

- Elytra without yellowish spot or bend

C. abstersus Bates

2. Elytral spot connected to apex 3

- Elytral spot not connected to apex

C. tetragonoderus Chaudoir

3. Length more $13 \mathrm{~mm}$, head and pronotum with strong reddish coppery luster in dorsal

- Length less than $13 \mathrm{~mm}$, head and pronotum with strong green or greenish luster in dorsal $\cdots . C$. hamifer Chaudoir

4. Spot of elytral apex located at interval 4 to 8

C. virgulifer Chaudoir

- Spot of elytral apex located at interval 3 to 8

C. pictus Chaudoir

\footnotetext{
$1 *$ Chlaenius hamifer Chaudoir, 1856 (Fig. 1)

Chlaenius hamifer Chaudoir 1856: 187.

Chlaenius bihamatus Chaudoir, 1856: 187.

Chlaenius queenslandicus Sloane, 1910: 435.
}

Material examined. Korea: $1 \overbrace{}^{\nearrow, ~ G y e o n g g i-d o, ~ S u w o n-s i, ~}$ 22 Jun 1999, Park JK.

Korean name: ${ }^{1 *}$ 녹색무늬먼지벌레 (신칭)

(c) This is an Open Access article distributed under the terms of the Creative Commons Attribution Non-Commercial License (http://creativecommons.org/ licenses/by-nc/3.0/) which permits unrestricted non-commercial use, distribution, and reproduction in any medium, provided the original work is properly cited.

pISSN 2234-6953 eISSN 2234-8190
*To whom correspondence should be addressed

Tel: 82-54-530-1215, Fax: 82-54-530-1218

E-mail: entopark@knu.ac.kr 


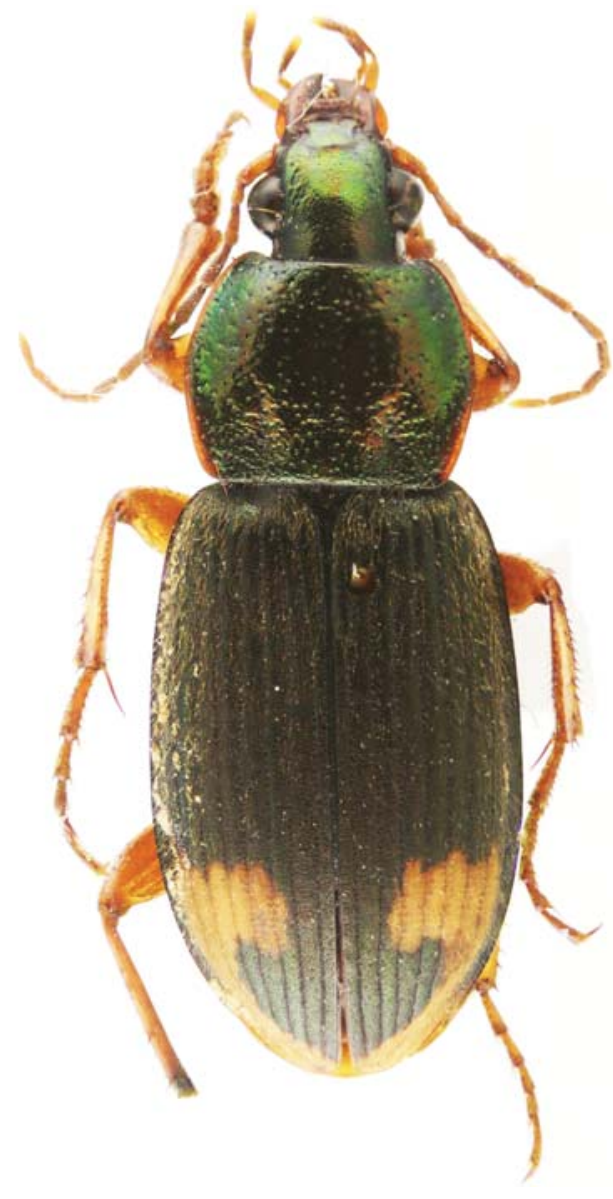

Fig. 1. Photo of Chlaenius hamifer Chaudoir from Korea (length $13 \mathrm{~mm}$ ).

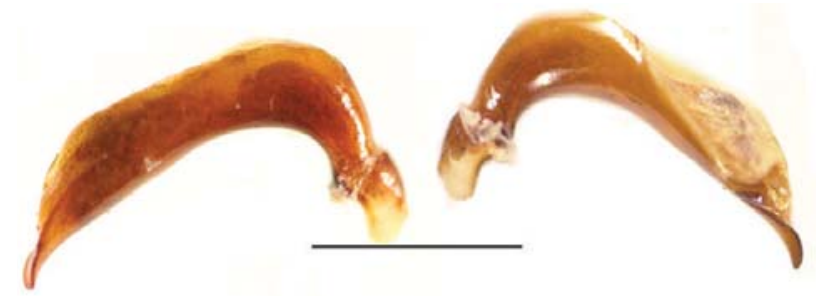

Fig. 2. Aedeagus of Chlaenius hamifer Chaudoir in lateral view. Scale bar $=1.9 \mathrm{~mm}$.

Description. Body length $13.0 \mathrm{~mm}$, width $5.2 \mathrm{~mm}$. Head and pronotum with strong greenish shiny, elytra dark brown, pronotum brown at latero-margin part. Antenna, labrum, mandible, palpi and legs yellowish brown. Ventral side black. Head: Relatively long, a little convex, dorsal side punctuate, with longitudinal rugose at laterodorsal area. Clypeus setae normal, antenna pubescent from 4th segment, palpi cyclindrical shape. Pronotum: A little convex, surface distinctly yel- lowish pubescent and deeply and largely punctuate than head disk, more concentrate at base, base with two fovea, a little wide and long, with transverse mashes at base, basal angle rounded. Elytra: Elongtely elliptic, widest near behind of middle, surface densely pubescent with small punctuate at interval and striae strongly and deeply punctuate, elytral apex with yellowish bend at interval 3 to 8 , connected to apex, middle side of bend combined to marginal area of apex. Legs: Yellowish brown, 5th segment of tarsus with ventral setae rows. Aedeagus (Fig. 2): Almost sickle shape, apex very hooked and twisted and concaved on dorsal view, right paramere wide and rounded at least 2.5 times more wide than left one, left paramere narrowed.

Notes. This species identified easily by greenish head and pronotm in dorsal and shape of yellowish bend at elytral apex (Nakane, 1986). And it is very similar to $C$. virgulifer, but distinguished by size, dorsal color and elytral bend shape.

Distribution. Korea (new record), Arab Emirates, Australia, Bhutan, China, Japan, Nepal, Pakistan, Oriental region.

\section{ACKNOWLEDGMENTS}

This study was supported by the project of the survey of Korean indigenous species of the National Institute of Biology Resources (NIBR) under the Ministry of Environment, Korea.

The photography system (Nikon SMZ-U, Japan) for this research was supported by Kyungpook National University Research Fund, 2012.

\section{REFERENCES}

Bonelli FA, 1810. Observation entomologiques. Première partie (cicindélètes et portion des carabiques) [with the "Tabula synoptica exhibens genera Carabicorum in sectiones et stirpes disposita"]. Turin, pp. 1-58.

De Chaudoir M, 1856. Mémoire sur la famille des Carabiques. 6e partie. Bulletin de la Société Impériale des Naturalistes de Moscou, 29:187-291.

Kirschenhofer E, 2003. Tribe Chlaeniini Brulle, 1834. In: Catalogue of Palaearctic Coleoptera. Vol. 1. Archostemata, Myxophaga, Adephaga (Eds., Löbl I, Smetana A). Apollo Books, Stenstrup, pp. 347-356.

Kuntzen H, 1919. Die Carabidenfauna Deutsch-Südwestafrikas. Mitteilungen aus dem Zoologischen Museum in Berlin, 9: 91-156.

Nakane T, 1986. The beetles of Japan (series 72). Insect and Nature, 21:19-24.

Park JK, Paik JC, 2001. Family Carabidae. Economic insects of Korea 12. Insecta Koreana Supplement, 19:1-170. 
Sloane TG, 1910. Revisional notes on Australian Carabidae. The Proceedings of the Linnean Society of New South Wales, 35:435-458.

The Entomological Society of Korea and Korean Society of Applied Entomology, 1994. Check list of insects from Korea.
Kon-Kuk University Press, Seoul, p. 130.

Received October 23, 2012

Revised December 10, 2012 Accepted December 16, 2012 